\title{
Surface Roughness and Translucency of Various Translucent Zirconia Ceramics after Hydrothermal Aging
}

\author{
Chaimongkon Peampring $^{1}$ Santiphab Kengtanyakich $^{1}$ \\ ${ }^{1}$ Department of Prosthetic Dentistry, Faculty of Dentistry, Prince of \\ Address for correspondence Chaimongkon Peampring, DScD, CAGS, \\ Songkla University, Hat Yai, Songkhla, Thailand \\ Department of Prosthetic Dentistry, Faculty of Dentistry, Prince of \\ Songkhla University, Hat Yai, Songkhla 90110, Thailand \\ Eur J Dent 2022;16:761-767. \\ (e-mail: mongkon.5c@gmail.com).
}

Abstract
Keywords
- zirconia
- hydrothermal aging
- surface roughness
- translucency
parameter
- contrast ratio

Objective This study investigated the effect of hydrothermal aging on surface roughness and translucency of various translucent zirconia materials.

Materials and Methods Four types of zirconia were tested. Group 1 was translucent zirconia with no cubic structure. Group 2, 3, and 4 included cubic-containing zirconia with different amounts of cubic structures (less than $30 \%, 30-50 \%$, and more than $50 \%$, respectively). Each group contained 15 disk-shape specimens with dimensions of $15 \mathrm{~mm}$ in diameter and $1 \mathrm{~mm}$ in thickness. As-sintered surface roughness, translucency parameter, and contrast ratio were evaluated in the two different sessions, before and after aging.

Statistical Analysis Two-way repeated measures ANOVA with Bonferroni test was used to analyze statistically significant difference in those tested parameters. Phase structure before and after aging was analyzed by X-ray diffraction analysis (XRD).

Results Groups 1 and 2 showed significant increased surface roughness after aging while groups 3 and 4 showed no alteration of surface. There was no effect of aging on translucency in all groups. After aging, group 1 and 2 presented monoclinic structure (16.63 and 5.01\%, respectively).

Conclusion Hydrothermal aging caused phase transformation and increasing surface roughness in group 1 and 2 but did not affect translucency in all groups.

\section{Introduction}

Yttrium oxide partially stabilized zirconia (3Y-TZP) or conventional zirconia consists of $3 \%$ mol of yttrium oxide $\left(\mathrm{Y}_{2} \mathrm{O}_{3}\right)$ as a stabilizer which helps in maintaining tetragonal crystal structure at room temperature. Tetragonal zirconia has high strength and fracture toughness due to tetragonal to monoclinic transformation around the crack tip after exposed to applied stress causing crack propagation termination. ${ }^{1,2}$ However, tetragonal zirconia has been susceptible to low temperature degradation or hydrothermal aging as it is immersed in water such as saliva. The aging process is a result of spontaneous transformation of the metastable tetragonal phase to the monoclinic in the presence of water at low temperatures which are approximately $30^{\circ} \mathrm{C}$ up to $400^{\circ} \mathrm{C}^{2,3}$ The progression of hydrothermal aging is relatively a slow process that starts on zirconia surface causing microcracks formation in the area of transformation. Crack propagation proceeds because of water penetration into the cracks leading to the intermolecular bond rupture of at the crack tip. This process results in a remarkable zirconia surface alteration and decrease in strength. ${ }^{4-6}$ The effect of aging occurs obviously in the case of lower yttrium oxide content. The published online

December 10, 2021
DOI https://doi.org/

$10.1055 / \mathrm{s}-0041-1736415$. ISSN 1305-7456. (c) 2021. The Author(s).

This is an open access article published by Thieme under the terms of the Creative Commons Attribution License, permitting unrestricted use, distribution, and reproduction so long as the original work is properly cited. (https://creativecommons.org/licenses/by/4.0/)

Thieme Medical and Scientific Publishers Pvt. Ltd., A-12, 2nd Floor, Sector 2, Noida-201301 UP, India 
initial powder consisting of increased amount of yttrium oxide can create the cubic crystal formation. Since cubic zirconia is a stable phase, it could resist to hydrothermal aging and has lower ability of transformation. ${ }^{7}$

The increased patients' aesthetic demands are driving the development of dental restorative materials from conventional zirconia which is apparently opaque to a highly translucent zirconia. Translucency is considered as an important factor in controlling aesthetics and plays an important role in decision of material selection. ${ }^{8}$ 3Y-TZP becomes more translucent by reducing size and repositioning of alumina grains resulting in improved light transmission. ${ }^{7}$ However, its aesthetic appearance is still far from mimicking natural dentition. Another way to improve zirconia translucency is increasing the amount of $\mathrm{Y}_{2} \mathrm{O}_{3}$ stabilizer that will alter the phase structure from tetragonal to cubic phase. The amount of $\mathrm{Y}_{2} \mathrm{O}_{3}$ stabilizer seems to have an effect on the overall microstructure of zirconia materials. The common amounts of $\mathrm{Y}_{2} \mathrm{O}_{3}$ added to improve translucency are 4 and 5\% mol (4Y-TZP and 5Y-TZP). ${ }^{9}$ Cubic crystal is the most stable phase structure; therefore, mechanical properties of cubic-containing zirconia seem to be stable after being hydrothermally aged. ${ }^{10}$ Even though cubic-containing zirconia (4Y-TZP and 5Y-TZP) is proved to resist to hydrothermal aging, some tetragonal crystals presenting in 4Y-TZP and 5Y-TZP are prone to be transformed to monoclinic phase spontaneously after being immersed in water in longterm period especially at the zirconia surfaces. Also, there is little evidence showing that the translucency of cubic-containing zirconia is stable after aging. Effect of hydrothermal aging usually appears at the zirconia surface so the surface topography and surface roughness of zirconia with different numbers of cubic crystals could have changed after being exposed to hydrothermal aging.

Therefore, the aim of this study was to investigate the effect of hydrothermal aging on translucency parameter (TP), contrast ratio (CR), and surface roughness of various types of translucent zirconia including noncubic and cubic-containing materials. The first null hypothesis was that there was no significant effect of hydrothermal aging on surface roughness and surface topography of all zirconia groups. The second hypothesis was that hydrothermal aging did not significantly affect translucency of all zirconia groups.

\section{Material and Methods}

\section{Specimen Preparation}

Four different types of zirconia were tested in this study (-Table 1). Fifteen disk-shaped specimens were prepared from each zirconia in a partially sintered stage using a precision saw (ISOMET 4000, Buehler Ltd., Lake Bluff, Illinois, United States). All specimens were sintering completely using high temperature furnace (Zyrcomat 6000 MS, VITA Zahnfabrik H. Rauter GmbH, Bad Sackingen, Germany) according to manufacturer's instructions. The final dimensions for each test specimen were $15 \mathrm{~mm}$ in diameter and $1 \mathrm{~mm}$ in thickness confirmed with a digital calliper (ABSOLUTE Digimatic Caliper, Mitutoyo Manufacturing Company Ltd, Kawasaki, Japan). Afterward, all specimens were cleaned with ultrasonic cleaner (Model: 460/M, Elma Schmidbauer $\mathrm{GmbH}$, Singen, Germany) for 10 minutes before testing. Hydrothermal aging simulation was set up using an autoclave oven (TOMY ES 215/ES-315, TOMY Kogyo) at $122^{\circ} \mathrm{C}$ under pressure of $2 \mathrm{~atm}$ for 8 hours. ${ }^{10}$ Each specimen was sealed in a sterilization pack and placed in the autoclave. After aging, all specimens were air-dried for 24 hours before testing.

\section{Surface Roughness Testing}

Surface topography evaluation and surface roughness measurements were performed in as-sintered specimens ( $n=15$ / each group) using a noncontact optical 3D surface measurement system (Infinite Focus SL, Alicona Imaging GmbH, Graz, Austria). The measurements were performed in both before and after aging condition.

\section{Translucency Measurement}

Translucency evaluation was interpreted from the measurement of TP and CR. TP was calculated by testing the color differences between the same specimens over the black and white backgrounds, according to the following formula ${ }^{11}$ :

$$
\mathrm{TP}=\left[\left(L^{*}{ }_{B}-L^{*}{ }_{W}\right)^{2}+\left(a^{*}{ }_{B}-a^{*}{ }_{W}\right)^{2}+\left(\boldsymbol{b}^{*}{ }_{B}-b^{*}{ }_{W}\right)^{2}\right]^{1 / 2}
$$

where the subscripts $B$ refers to the color coordinates over the black background and $W$ is the color coordinates over the white background. A higher TP value indicates a higher translucency.

The CR was calculated from the spectral reflectance of light of the specimen $(Y)$ over black $\left(Y_{B}\right)$ and white $\left(Y_{W}\right)$ backgrounds, using the following equations:

$$
\begin{gathered}
Y=\left[\left(L^{*}+16\right) / 116\right]^{3} \times 100 \\
\mathrm{CR}=Y_{B} / Y_{W}
\end{gathered}
$$

The $C R$ is 0.0 for a transparent material and 1.0 for a totally

\begin{tabular}{|c|c|c|c|c|}
\hline Group & Material & Amount of cubic (\%vol) & Lot number & Manufacturers \\
\hline 1 & 3Y-TZP & 0 & 73830 & VITA Zahnfabrik. Bad Säckingen, Germany \\
\hline 2 & 4Y-TZP & $<30$ & 65890 & VITA Zahnfabrik. Bad Säckingen, Germany \\
\hline 3 & $5 Y-T Z P$ & $30-50$ & 61960 & VITA Zahnfabrik. Bad Säckingen, Germany \\
\hline 4 & $5 Y-T Z P$ & $>50$ & ZB6124B & Zirkonzahn GmbH, Bruneck, Italy \\
\hline
\end{tabular}
opaque material. ${ }^{11}$

Table 1 Various types of zirconia and their designated group used in the present study 
Translucency evaluation was done in the same specimens used for surface evaluation. A spectrophotometer (ColorQuest XE, Hunter Associates Laboratory, Inc., Reston, Virginia, United States) with a calibration plate and port size of 0.375 inches was used to record the CIELAB coordinates $\left(L^{*}, a^{*}\right.$, and $\left.b^{*}\right)$ of zirconia disks. The TP and CR measurements were performed in both before and after aging.

\section{Phase Structure Analysis}

Phase identifications of each group before and after aging were done by X-ray diffraction (Philips X'Pert MPD, Philips, Eindhoven, Netherlands) using $\mathrm{Cu}-\mathrm{K} \alpha$ radiation from 0 to 90 degrees (2 $\theta$ ). Scans were performed at $40 \mathrm{kV}, 30 \mathrm{~mA}$, step size of 0.05 degrees/step, and a scan time of $1 \mathrm{~s} / \mathrm{step}$. The phase structures were refined as: tetragonal zirconia $(t)$, monoclinic zirconia $(\mathrm{m})$, cubic zirconia (c) and data was indexed as a library data. The crystalline phase fraction was reported as the peak position of each crystal structure. $\mathrm{X}$-ray diffraction analysis (XRD) outputs were mapped with library data to detect the crystal structure on the surface of materials and volume fraction of monoclinic transformation was calculated according to studies by Toraya and Yoshimura $^{12}$ and Garvie and Nichoson. ${ }^{13}$

\section{Statistical Analysis}

Two-way repeated measures ANOVA with Bonferroni test was used to determine the differences in TP, CR, and surface roughness comparing before and after aging among various types of zirconia. The statistical analysis was performed using SPSS software, version 24.0 (SPSS, IBM) to detect statistically significant differences $(\alpha=0.05)$.

\section{Results}

Surface topography results, which are based on visual inspection showed that group 1 presented irregular surface in all areas of testing ( - Fig. 1A, B) and followed by group 2 ( - Fig. 1C, D). However, each group revealed no changing on the surface after aging. Two-way repeated ANOVA results showed significant differences in surface roughness $(\mathrm{Ra})$ values among the material groups and aging conditions $(p<0.05)$, while there was no statistically significant interaction between two independent factors $(p=0.066)$. Group 1 had a significant difference in surface roughness comparing between specimens in before aging condition $(263.201 \pm 15.888 \mathrm{~nm})$ and after aging condition $(325.048 \pm 18.047 \mathrm{~nm})$. In addition, group 2 showed significant increase in surface roughness after aging (from $201.209 \pm 17.681$ to $228.330 \pm 12.248 \mathrm{~nm}$ ). Groups 3 and 4 presented no alteration on surface roughness (-Fig. 2 ).

According to translucency evaluation, there was a significant difference in TP values (-Table 2 ) based on material difference $(p<0.05)$. No significant difference based on aging conditions $(p=0.156)$ and interaction effect $(p=0.274)$ was detected. Group 1 showed the lowest TP value whether it was aged or not, significantly. Group 2 showed significantly lower TP value compared with groups 3 and 4 only in aged specimens. Groups 3 and 4 showed no significant difference in TP values regardless of aging condition $(p>0.05)$. The $C R$ values

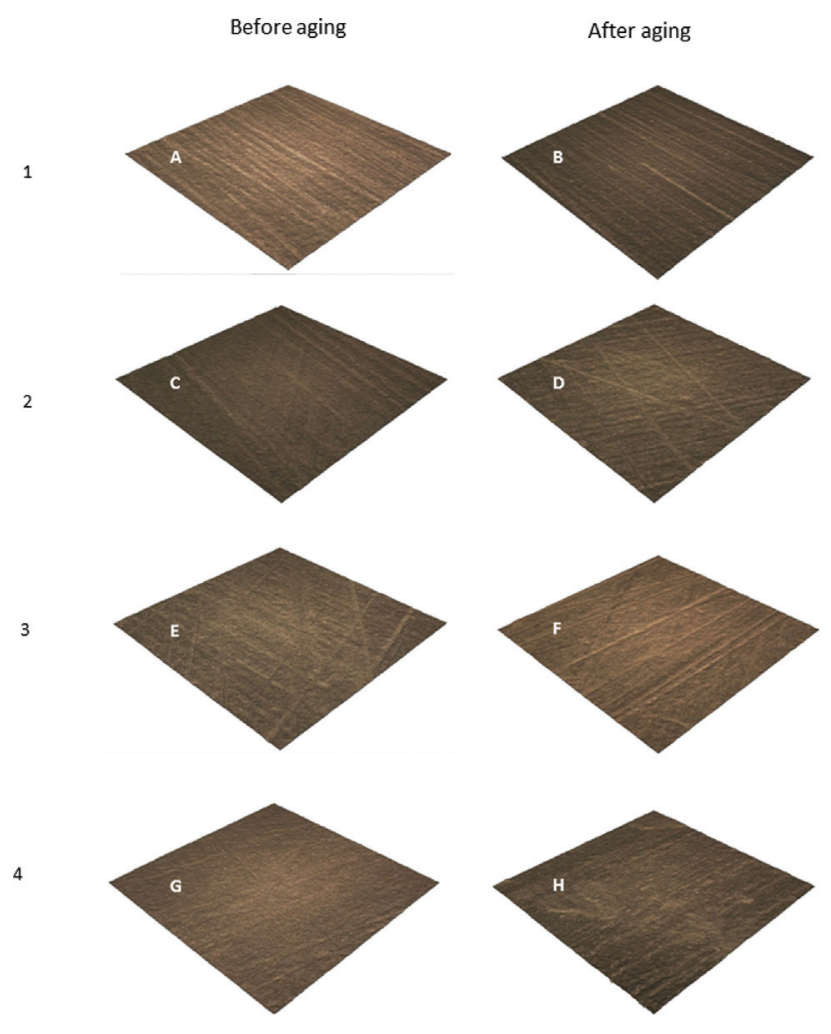

Fig. 1 Surface topography of all experimental groups in each aging condition (surface area of $1.25 \mathrm{~mm}$ for testing at magnification of $50 \times$ ). (A) Group 1 before aging; (B) group 1 after aging; (C) group 2 before aging; (D) group 2 after aging; (E) group 3 before aging; (F) group 3 after aging; (G) group 4 before aging; (H) group 4 after aging.

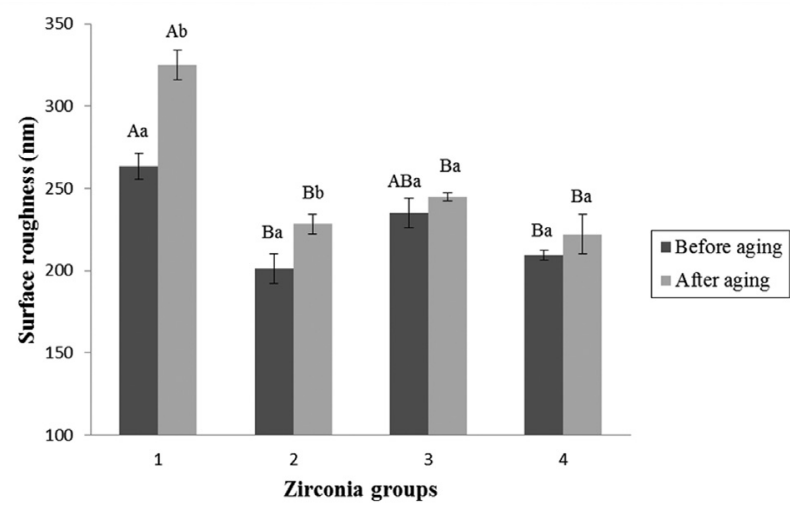

Fig. 2 Surface roughness ( $R a$ ) values (mean $\pm S D$ ) of the different experimental groups. Different uppercase letters indicate statistically significant among material group $(p<0.05)$. Different lowercase letters indicate statistically significant comparing before and after aging within group $(p<0.05)$.

are reported in - Table 3 . The results showed statistically significant difference between the material groups $(p<0.05)$. The mean $C R$ value of group 1 was significantly the highest value. The $\mathrm{CR}$ values can be ranked as follow: group $4=3<2$ $<1$ regardless of aging condition. After aging, CR values appeared to be no change statistically comparing within material group $(p=0.126)$. Therefore, there was no significant change in translucency within material group comparing before and after aging. 
Table 2 Mean \pm SD of translucency parameter (TP) in all groups

\begin{tabular}{|l|l|l|}
\hline \multirow{2}{*}{ Group } & \multicolumn{3}{|l|}{ Translucency parameter } \\
\cline { 2 - 3 } & Before aging $(\boldsymbol{n}=15)$ & After aging $(\boldsymbol{n}=\mathbf{1 5})$ \\
\hline 1 & $6.574 \pm 0.867^{\mathrm{Aa}}$ & $6.268 \pm 0.821^{\mathrm{Aa}}$ \\
\hline 2 & $9.794 \pm 0.226^{\mathrm{Ba}}$ & $9.649 \pm 0.216^{\mathrm{Ba}}$ \\
\hline 3 & $10.001 \pm 0.319^{\mathrm{Ba}}$ & $10.068 \pm 0.289^{\mathrm{Ca}}$ \\
\hline 4 & $10.018 \pm 0.772^{\mathrm{Ba}}$ & $10.099 \pm 0.253^{\mathrm{Ca}}$ \\
\hline
\end{tabular}

Note: Different uppercase letters in the same column indicate statistically significant difference $(p<0.05)$; Different lowercase letters in the same row indicate statistically significant difference $(p<0.05)$.

The phase structure analysis using XRD showed that no monoclinic phase was detected in all groups before aging. After aging, the peaks representing monoclinic structure were seen in groups 1 and 2 (-Figs. 3 and 4). The amount of monoclinic phase detected in groups 1 and 2 were up to 16.63 and $5.01 \%$, respectively. There was no detected monoclinic phase after aging in groups 3 and 4 .

\section{Discussion}

Conventional zirconia containing $3 \%$ mol of yttrium oxide retains tetragonal crystal and no cubic crystal presented at room temperature. A benefit of having tetragonal crystal
Table 3 Mean \pm SD of contrast ratio $(C R)$ in all groups

\begin{tabular}{|l|l|l|}
\hline \multirow{2}{*}{ Group } & Contrast ratio \\
\cline { 2 - 3 } & Before aging $(\boldsymbol{n}=15)$ & After aging $(\boldsymbol{n}=15)$ \\
\hline 1 & $0.838 \pm 0.021^{\mathrm{Aa}}$ & $0.847 \pm 0.020^{\mathrm{Aa}}$ \\
\hline 2 & $0.745 \pm 0.005^{\mathrm{Ba}}$ & $0.746 \pm 0.005^{\mathrm{Ba}}$ \\
\hline 3 & $0.728 \pm 0.007^{\mathrm{Ca}}$ & $0.729 \pm 0.006^{\mathrm{Ca}}$ \\
\hline 4 & $0.726 \pm 0.008^{\mathrm{Ca}}$ & $0.727 \pm 0.020^{\mathrm{Ca}}$ \\
\hline
\end{tabular}

Note: Different uppercase letters in the same column indicate statistically significant difference $(p<0.05)$; Different lowercase letters in the same row indicate statistically significant difference $(p<0.05)$.

structure is the transformation toughening of zirconia material. ${ }^{14,15}$ Therefore, 3Y-TZP has superior mechanical properties compared with other dental ceramics. ${ }^{16-18} \mathrm{~A}$ drawback of retaining tetragonal phase structure at room temperature is opacity of a material thus it can be used as a high strength substructure of a crown which has to be veneered with higher aesthetic materials. ${ }^{19,20}$ Zirconia translucency can be improved by either modifying microstructure or increasing the amount of $\mathrm{Y}_{2} \mathrm{O}_{3} .{ }^{21}$ Translucent zirconia tested in this study could be varied based upon the amount of cubic structure. Group 1 was zirconia with no cubic crystal while group 2, 3, and 4 included cubiccontaining zirconia with different amount of cubic crystal

A
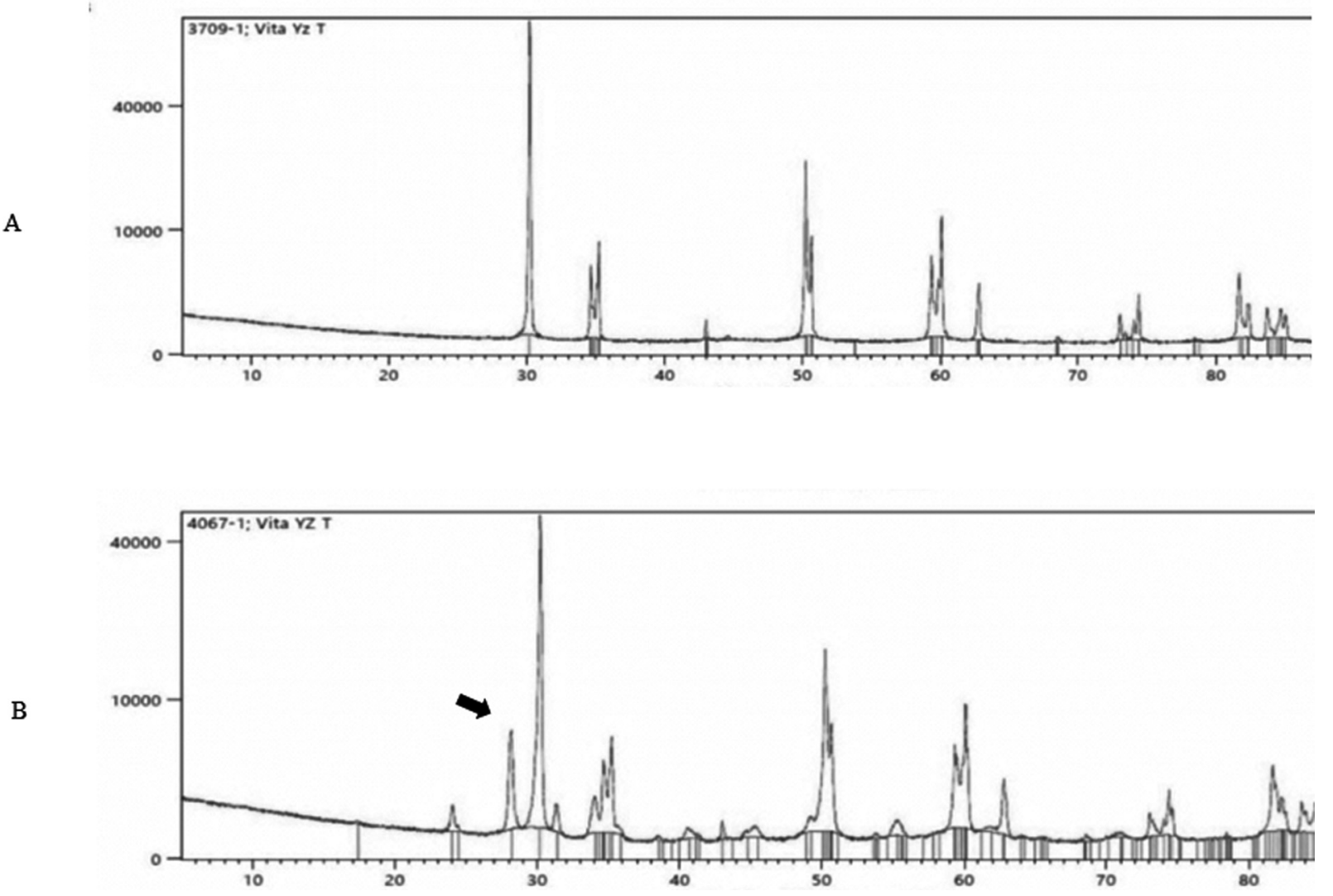

Fig. 3 Phase structure from XRD results for group 1. The black arrow indicates peak of monoclinic phase, (A) before aging, (B) after aging. XRD, X-ray diffraction. 

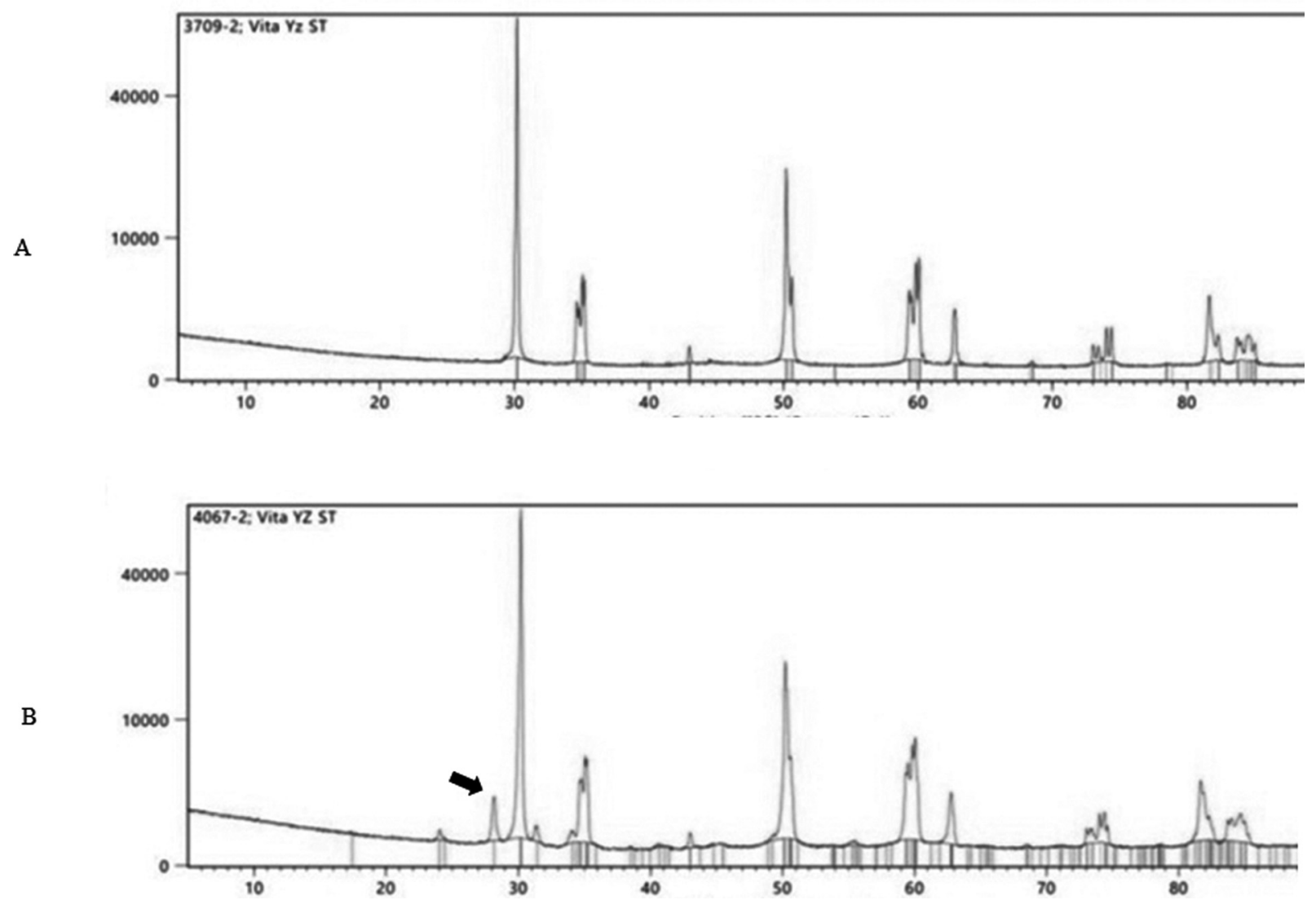

Fig. 4 Phase structure from XRD results for group 2. The black arrow indicates peak of monoclinic phase, (A) before aging; (B) after aging. XRD, X-ray diffraction.

(30\%, 30-50\%, and more than 50\%, respectively). Since, hydrothermal degradation, a spontaneous transformation from the metastable tetragonal to the monoclinic structured facilitated by oral fluid, usually takes place on the zirconia surface, this study aimed to evaluate surface alteration and translucency change of all experimental group under extreme in vitro aging conditions. This accelerated hydrothermal aging was performed in an autoclave at $122^{\circ} \mathrm{C}$ under constant pressure of 2 atm for 8 hours. It is possible to assume that 1 hour of autoclaving has the same effect as 1 year in clinical services. ${ }^{6}$

Surface roughness evaluation among various types of translucent zirconia and aging condition showed significant difference; therefore, the first null hypothesis was rejected. To eliminate the influence of surface polishing protocol, the surface roughness in this study had been tested on assintered specimens. The results showed that hydrothermal aging affected the Ra in group 1 and 2 due to the progressive spontaneous transformation of the metastable tetragonal phase to the monoclinic phase in the presence of oral fluid. $^{2,22}$ This could be confirmed by XRD results showing detected monoclinic in group 1 and 2 after aging. It is in accordance with some previous studies showing that surface deterioration occurred in a zirconia material. ${ }^{23}$ Groups 3 and 4 retained large amounts of cubic structure, the most stable crystal structure; at room temperature thus phase transformation would not occur after being accelerated by hydrothermal aging. A threshold surface roughness below $0.2 \mu \mathrm{m}$ could be considered as a smooth surface, in which, no further bacterial accumulation could be expected. ${ }^{24,25}$ The roughness threshold detectable by the tongue was more than $0.5 \mu \mathrm{m} .{ }^{26}$ Mean Ra values of aged specimens in group 1 $(0.325 \mu \mathrm{m})$ and $2(0.228 \mu \mathrm{m})$ were less than the threshold that can be detected by tongue.

The second null hypothesis was accepted because the optical properties of the cubic zirconia material were not influenced by hydrothermal aging. There was no significant effect of aging on translucency of zirconia. Translucency of restorative material affects esthetic outcome of restorations by mimicking natural appearance. Patients are concerned more about esthetic outcome so translucency of zirconia material should be investigated. ${ }^{27}$ Residual porosity and zirconia grain size are the main factors controlling light transmission. Transformation of tetragonal crystal to monoclinic crystal results in increasing grain size. ${ }^{22}$ Therefore, the assumption of hydrothermal aging affecting zirconia translucency could be possible. However, the transformation occurred only at the surface of material which was not affecting the overall grain size and translucency which was confirmed by this study. Zirconia translucency was evaluated by measuring TP and CR. The TP was determined by calculating the color differences in the same specimen against black and white backgrounds. A higher TP value indicated a higher translucency. On the contrary, the CR was calculated from the light spectral reflectance of the same specimen over a black and a white background, the CR is range from 0.0 and 
1.0 , in which 0.0 means a material is transparent material and 1.0 means a material is totally opaque. ${ }^{11}$ Group 1 presented less translucent than cubic-containing groups (2, 3 , and 4 ) and group 2 presented no significant difference in TP values compared with groups 3 and 4 . However, the $C R$ in group 2 was lower than groups 3 and 4 . These results could be explained in which TP value was determined based on CIELAB color parameter using $L^{*} a^{*} b^{*}$ data. Nevertheless, $a^{*}$ and $b^{*}$ are hue values which were achieved from color pigments. Each material contained different amount of color pigments resulting in a different hue value. This might affect the TP value. This study showed that zirconia with cubic structure had high translucency since the cubic zirconia is optically isotropic without light scattering at the grain boundaries. ${ }^{21,23}$ Thus, zirconia ceramics with a slight variation in cubic structure resulted in a substantially different translucency. The strategy of increasing the amount of cubic crystals resulted in higher translucency of zirconia. ${ }^{28,29} \mathrm{~A}$ previous study concluded that high translucency monolithic zirconium oxide materials had TP values in the range of 14.6 to 23.2. ${ }^{30}$ TPs of our study showed lower values than the previously mentioned study because of different surface finishing protocols resulting in differences in smoothness of the surfaces, leading to decreased light scattering, and higher TP values. ${ }^{31}$ All specimens in this study were tested in as-sintered condition; therefore, this could be a cause of lower translucency.

Phase transformation after aging was confirmed with X-ray diffraction analysis. The results showed that there was no monoclinic phase presented after hydrothermal aging in groups 3 and 4 . The results indicated that the high amount of cubic crystal caused a more stable condition of zirconia; therefore, phase transformation did not occur. The present results were in accordance with a previous study evaluating the aging stability of 5Y-TZP. The authors reported that cubiccontaining zirconia did not show any transformation after 300 hours of accelerated aging. ${ }^{6}$ In our study, group 2 exhibited some monoclinic crystals (approximately 5.01\%) after hydrothermal aging for 8 hours, which was possible because of less amount of yttrium oxide stabilizer added. ${ }^{16}$ For group 1 , the presence of monoclinic phase after autoclave aging coincided with the previous study which evaluated the amount of monoclinic phase on XRD after 8 hours of aging. ${ }^{10}$ They also found that hydrothermal aging did not alter mechanical properties of cubic-containing zirconia. ${ }^{10}$ However, this study found that the hydrothermal aging resulted in surface alteration of noncubic translucent zirconia and cubic-containing zirconia which consisted of less than $30 \%$ of cubic crystals. Further study should investigate the effect of hydrothermal aging on surface gloss of highly polished zirconia.

\section{Conclusion}

Within the limitations of this in vitro study, the following conclusions were drawn: hydrothermal aging in autoclave for 8 hours caused phase transformation and increasing surface roughness only in group 1 (noncubic) and 2 (cubic less than 30\%). However, surface roughness of groups 3 and 4 was not affected by hydrothermal aging. Also, hydrothermal aging did not affect translucency of all zirconia materials.

\section{Funding}

This study received its funding by the Technologies and Materials in Digital Dentistry Research Unit, Faculty of Dentistry, Prince of Songkla University.

\section{Conflict of Interest}

None declared.

\section{Acknowledgments}

The authors wish to acknowledge Centre of Excellency in Maxillofacial Prosthesis, for providing equipment for specimen preparation.

\section{References}

1 Denry I, Kelly JR. State of the art of zirconia for dental applications. Dent Mater 2008;24(03):299-307

2 Chevalier J, Gremillard L, Virkar AV, Clarke DR. The tetragonalmonoclinic transformation in zirconia: lessons learned and future trends. J Am Ceram Soc 2009;92:1901-1920

3 Haraguchi K, Sugano N, Nishii T, Miki H, Oka K, Yoshikawa H. Phase transformation of a zirconia ceramic head after total hip arthroplasty. J Bone Joint Surg Br 2001;83(07):996-1000

4 Chevalier J. What future for zirconia as a biomaterial? Biomaterials 2006;27(04):535-543

5 Lawson S. Environmental degradation of zirconia ceramics. J Eur Ceram Soc 1995;15:485-502

6 Chevalier J, Cales B, Drouin JM. Low-temperature aging of Y-TZP ceramics. J Am Ceram Soc 1999;82:2150-2154

7 Stawarczyk B, Keul C, Eichberger M, Figge D, Edelhoff D, Lümkemann N. Three generations of zirconia: from veneered to monolithic. Part I. Quintessence Int 2017;48(05):369-380

8 Kelly JR, Nishimura I, Campbell SD. Ceramics in dentistry: historical roots and current perspectives. J Prosthet Dent 1996;75(01):18-32

9 Kontonasaki E, Giasimakopoulos P, Rigos AE. Strength and aging resistance of monolithic zirconia: an update to current knowledge. Jpn Dent Sci Rev 2020;56(01):1-23

10 Kengtanyakich S, Peampring C. An experimental study on hydrothermal degradation of cubic-containing translucent zirconia. J Adv Prosthodont 2020;12(05):265-272

11 Della Bona A, Nogueira AD, Pecho OE. Optical properties of CADCAM ceramic systems. J Dent 2014;42(09):1202-1209

12 Toraya H, Yoshimura M, Somiya S. Calibration curve for quantitative analysis of the monoclinic-tetragonal ZrO2 system by $\mathrm{x}$-ray diffraction. J Am Ceram Soc 1984;67:119-121

13 Garvie RC, Nicholson PS. Phase analysis in zirconia systems. J Am Ceram Soc 1972;55:303-305

14 Gracis S, Thompson VP, Ferencz JL, Silva NR, Bonfante EA. A new classification system for all-ceramic and ceramic-like restorative materials. Int J Prosthodont 2015;28(03):227-235

15 Juntavee N, Uasuwan P. Flexural strength of different monolithic computer-assisted design and computer-assisted manufacturing ceramic materials upon different thermal tempering processes. Eur J Dent 2020;14(04):566-574

16 Kim JW, Covel NS, Guess PC, Rekow ED, Zhang Y. Concerns of hydrothermal degradation in CAD/CAM zirconia. J Dent Res 2010; 89(01):91-95

17 Nawafleh N, Bibars AR, Al Twal E, Öchsner A. Influence of antagonist material on fatigue and fracture resistance of zirconia crowns. Eur J Dent 2020;14(02):200-205

18 Lughi V, Sergo V. Low temperature degradation -aging- of zirconia: a critical review of the relevant aspects in dentistry. Dent Mater 2010;26(08):807-820 
19 Peampring C, Aksornmuang J, Sanohkan S. In vitro fracture resistance of composite-resin-veneered zirconia crowns. J Conserv Dent 2017;20(04):225-229

20 Mesquita AMM, Al-Haj Husain N, Molinero-Mourelle P, Özcan M. An intraoral repair method for chipping fracture of a multi-unit fixed zirconia reconstruction: a direct dental technique. Eur J Dent 2021;15(01):174-178

21 Zhang F, Inokoshi M, Batuk M, et al. Strength, toughness and aging stability of highly-translucent Y-TZP ceramics for dental restorations. Dent Mater 2016;32(12):e327-e337

22 Guo X. Property degradation of tetragonal zirconia induced by low-temperature defect reaction with water molecules. Chem Mater 2004;16:3988-3994

23 Yang $\mathrm{H}, \mathrm{Xu}$ YL, Hong G, Yu H. Effects of low-temperature degradation on the surface roughness of yttria-stabilized tetragonal zirconia polycrystal ceramics: a systematic review and meta-analysis. J Prosthet Dent 2021;125(02): 222-230

24 Bollen CM, Lambrechts P, Quirynen M. Comparison of surface roughness of oral hard materials to the threshold surface roughness for bacterial plaque retention: a review of the literature. Dent Mater 1997;13(04):258-269
25 Beltrami R, Ceci M, De Pani G, et al. Effect of different surface finishing/polishing procedures on color stability of esthetic restorative materials: a spectrophotometric evaluation. Eur J Dent 2018;12(01):49-56

26 Jones CS, Billington RW, Pearson GJ. The in vivo perception of roughness of restorations. Br DentJ2004;196(01):42-45, discussion 31

27 Tiro A, Nakas E, Arslanagic A, Markovic N, Dzemidzic V. Perception of dentofacial aesthetics in school children and their parents. Eur J Dent 2021;15(01):13-19

28 Putra A, Chung KH, Flinn BD, et al. Effect of hydrothermal treatment on light transmission of translucent zirconias. J Prosthet Dent 2017;118(03):422-429

29 Peuchert U, Okano Y, Menke Y, Reichel S, Ikesue A. Transparent cubic- $\mathrm{ZrO}_{2}$ ceramics for application as optical lenses. J Eur Ceram Soc 2009;29:283-291

30 Church TD, Jessup JP, Guillory VL, Vandewalle KS. Translucency and strength of high-translucency monolithic zirconium oxide materials. Gen Dent 2017;65(01):48-52

31 Akar GC, Pekkan G, Çal E, Eskitaş̧̧ıŏlu G, Özcan M. Effects of surface-finishing protocols on the roughness, color change, and translucency of different ceramic systems. J Prosthet Dent 2014; 112(02):314-321 